\title{
An Experience of Optimizing A Community-Based Micro-Insurance Model to Bridge the Gap between Treatment Cost and Ability to pay at BPKIHS
}

\author{
Narayan Kumar,' Shekhar Koirala, ${ }^{2}$ Mamta Varma ${ }^{3}$ \\ 'Ex-Hospital Administration, B.P. Koirala Institute of Health Science, Dharan, Nepal, ${ }^{2}$ Ex-Vice Chancellor, B.P. Koirala \\ Institute of Health Science, Dharan, Nepal, ${ }^{3}$ Gynecology and Obestretics Awadh Narayan Memorial Clinic, Biratnagar, \\ Nepal.
}

\section{ABSTRACT}

In the year 2001 the leaders of BPKIHS started a micro social insurance scheme; Social Health Insurance (SHI) for prospective research. It is a method of financing and managing health care using compulsory contributions from employers, employees and may be from the government.

Household members from organized groups in catchment areas enrolled voluntarily. Photographed service cards were issued entitled for free IPD/OPD consultations, investigations and bed charges excluding CT scans and specialty treatment. Institute bore operation and medicine costs up to 10000 and 3500 respectively for IPD yearly. Premium was fixed after a research through focus group discussion in villages of Morang, Sunsari and Biratnagar. A flat rate premium of 15 and 50 NRS/ adult/month for villagers, city dwellers and half for children was fixed. Marginalized community and handicapped paid 33\% of premium, 33\% by Institute and 33\% by concerned VDC.

As the client number increased from 2383 to 7392 in second and to 15779 in third year, Premium: Expenditure ratio moved from 225:222 to 198:391. Average cost sharing of premium to expenditure came to $226: 332$ showing a negative 3alance.

This scheme completed its fourth year till this research in 2005 A.D. But it was closed due to deficit. As reinsured population occasionally concealed information by not incorporating all family members. They defaulted in subsequent year after utilizing the benefits of SHI and misused the card for uninsured ones. It may, in its optimized form, become a model to be widely adopted to bridge the gap between the cost of treatment and the ability to pay in developing countries.

Keywords: community health; health financing; micro-finance; social health insurance.

\section{INTRODUCTION}

Social Health Insurance (SHI) may be categorized as micro social insurance scheme as per the definition. This is unique in nature from other such similar schemes known globally in a sense that it covered informal as well as formal sector of villagers and city dwellers. ${ }^{1-3}$

All the government hospitals in Nepal are subsidized but their prices vary consultation and hospital stay charge is having higher subsidy. Private hospitals are costly, which general people cannot afford, thus ignore the

Correspondence: Dr. Narayan Kumar, Anam Kutir, Cha-79, Biratnagar-9, Nepal. Email: kumarnarain@yahoo.com, Phone: +9779852025883 
disease till they can tolerate. Once the patient spends more than NRs. 1000/- their money is exhausted and have to go back either to take loan from money lenders or sell their livestock.4-6

The objective of this study was to develop, iteratively test, modify and optimize a community - based "healthy share of the cost of treatment of sick" model to bridge the gap between costs of treatment and ability to pay.

\section{SHI IN BPKIHS}

In mission statement of BPKIHS the word 'socially accountable', 'Innovation', and 'Research' forced the inventors to think alternative financial method for poor people. SHI had to cater to the people's health expenditure needs. ${ }^{1}$ The idea was that, "People should not remain devoid of health care because of lack of money. . $^{5-8}$

SHI was conducted as an experiment for health prospective system research done in three years; 2001, 2002 and 2003 in tertiary care center, Dharan, Nepal and its outreach services. Members of the household from organized groups in catchment areas such as VDCs, municipalities, sociocultural organizations, schools, companies, associations and individuals voluntarily enrolled. All Family members enrolled through their heads with "all photograph" bearing service card by BPKIHS at a monthly rate of Rs.15/-per adult in rural and Rs.50/- per adult in the urban population. Children were enrolled at half the rate. They were entitled for free IPD/OPD consultations, investigations and bed charges. Operation costs up to $10000 /-$ per year and medicine up to 3500 per year for IPD patients were born by the institute. CT scans and specialty treatment like dialysis were excluded.

\section{PREMIUM FIXATION}

It was done through focus group discussions to decide on ability to pay. Main outcome measures: Number enrolling/ defaulting, biased enrolment of adverse risk participant were monitored and used to make micro-corrections in the running of the system. The scheme SHI had to cater to the people's health expenditure needs. Awareness was created and the groups were formed. The group leader was responsible for collecting the premium and as well as required information and pass it on to SHI section, BPKIHS. SHI of BPKIHS was based on social solidarity, contribution on ability to pay, nonprofit concept and compulsory for all members of the household. It also takes care of international labor standards i.e., social security (minimum standard). ${ }^{2}$

The premium was fixed after a research through focus group discussion in different villages of Morang, Sunsari and Biratnagar city. The consensus was reached for flat rate premium $^{3}$ of $15 \mathrm{NRS/} \mathrm{adult} \mathrm{person/} \mathrm{month} \mathrm{for} \mathrm{villagers}$ and 50 NRS/ adult person/ month for city dwellers. The premium for child was half the adult premium respectively. All the family members of house had to take the policy compulsorily. People from marginalized community as well as handicapped had to pay $33 \%$ of premium rest $33 \%$ was given by Institute and $33 \%$ by concerned VDC this prevented the exclusion of such community due to lack of money. SHI scheme was based on "No profit no loss" basis. To reduce the administrative cost, collection of premium was the responsibility of VDC/NGO/INGO or the leader of the groups who are interested in the scheme. Also they were asked to identify the marginalized and handicapped in their group. They were given support to make available all the Names, Photograph and other required parameters as per the format of the scheme form. In the beginning the cards were distributed during a small orientation program so as to make people aware of functioning of the scheme.

After receiving the money for the institute insurance section was given them the receipt of the money and the insurance card for each family household to come for checkups when it is required. Members of scheme had a card with photograph, name and address on it which was treated as OPD/ Inpatient ID. After the registration of the date they were asked to report in GOPD where a Generalist (MDGP) will assess their cases and prescribe, refer to specialist or admit for further treatment action. The medicine/investigation etc. is to be posted on the card. To use the hospital facility all the members were required to come with card. The benefits of the scheme/person/year in the OPD were unlimited consultation and investigation in any department. Whereas, in inpatient category; consultation and investigation with use of general bed was unlimited. Medicine was provided amount of 3500 yearly and a surgical charge of 10,000 yearly.

Another important decision was that the premium will be kept in separate bank account and the interest earned will be utilized for excess expenditure incurred. This was also not projected in the calculation. As there is no employee therefore formal was defined as those who are in Job and earning and to some extent the farmer also. The household may be assumed as employed and other will be covered by their employed guardian. Like husband and wife and vice versa, old mother and child. Sampling was done in random (Table 3). Institute was to take care of excess by different method as explained earlier. The contributions were based on ability to pay therefore a flat rate was decided as Institute believed that $\mathrm{SHI}$ should be a nonprofit concept. It was made very clear as regard method of $\mathrm{SHI}$ where individual health risk (preexisting conditions, age, disability, etc.) do not influence the level of contributions and do not inevitably lead to exclusion from protection. 


\section{INSURANCE POLICY}

Types of diseases covered were all the acute cases, normal/ caesarean delivery and all types of surgery available in the Institute. It served tuberculosis \& leprosy through national control program. Whereas in dental OPD consultation, only zinc oxide filling was covered. Exclusion was made for CT scan, TMT Echocardiography, Hemodialysis, Prosthesis, Implants, etc. that are not available in hospital.

Here institute failed to endorse its policy and to explain that it was innovation and therefore included both formal and informal ${ }^{4}$ sector so cost will only partly be taken care of by the institute. This was planned as a health provider insurance section will negotiate a subsidy from authority as it was buying the services in bulk in a given time especially investigation charges like any other place. While calculating the expenditure, bulk discount was planned, it was not included while calculating the premium VS Expenditure ratio.

\section{BPKIHS EXPERIENCE}

First year client number 2383 increased to 7392 in second year and went up to 15779 in third year. Premium versus expenditure ratio moved from 225:222 in the first year to $198: 391$ in the third year. Average 3 years cost sharing of premium to expenditure comes to 226:332. Cost minimization and biased adverse risk among the problems that need control. Above mentioned data were analyzed and following reasons of negative balance were found (Table 1).

A total of $45 \%$ availed of OPD services out of which 9.6\% needed inpatient admission (Table 2). Average expenditure under categories and common morbidity patterns in outpatient departments are given in Table 4 and 5 respectively.

Defaulter increased up to $50 \%$ in groups which directly influenced the concept of SHI i.e. - philosophy of SHI to have right of treatment during sickness and pay when they are healthy. Major grievances among the defaulting clients were lack of money $(7 \%)$, quality of hospital service is not satisfactory $(3.63 \%)$, difficulty to get hospital services (4.11\%), unknown cause (3.64\%) and interested to rejoin (6.29\%) (Table 3-5).

The population who were reinsured occasionally concealed the information by not incorporating all family members and also defaulted in subsequent year after once utilizes the benefits of SHI. They also misused the card for people who were not insured. Hence, the original concept of social health insurance failed i.e. Burden of direct cost of medical care for the patient to be spread (Table 1) either over a period of time rather than having to be made at the time and point of delivery. Also among a group of people who share the risk of costs of medical care.

As the concept of social solidarity was taken care of by involving city people with 3 times more premium charged that of villagers (Table 4). Hence villagers started concealing the address as one member is earning and staying in city permanently but they paid less by giving wrong address. Some other identified reasons for deficit of expenditure included increased use of investigation facility by urban people with lower number of insured household and premium by influencing the doctor. Pressure and increased use by staff and students of BPKIHS for others who are not insured resulting in any cross subsidy failure.

\begin{tabular}{|lllllll|}
\hline \multicolumn{2}{|l}{ Table } & 1. Number of households, members and premium. \\
\hline Year & $\begin{array}{l}\text { Member } \\
\text { number }\end{array}$ & $\begin{array}{l}\text { No. of } \\
\text { Household }\end{array}$ & $\begin{array}{l}\text { Premium } \\
\text { NRS }\end{array}$ & Expenditure & $\begin{array}{l}\text { Cost Sharing of premium vs. } \\
\text { expenditure ratio. }\end{array}$ & $\begin{array}{l}\text { Organization } \\
\text { number }\end{array}$ \\
2057 & 2383 & 565 & 538051 & 531388 & $225: 222$ & 8 \\
2058 & 7392 & 2540 & 1888604 & 2831356 & $255: 383$ & 26 \\
2059 & 15779 & 3587 & 3116495 & 6181237 & $198: 391$ & 32 \\
\hline
\end{tabular}

\begin{tabular}{|lll|}
\hline \multicolumn{2}{|l|}{$\begin{array}{l}\text { Table } \\
\text { years. }\end{array}$} & Utilization of Services department wise 3 \\
\hline Year & Outpatient Number & Inpatient Number \\
2057 & $834(31.9 \%)$ & $77(9.2 \%)$ \\
2058 & $3305(44.7 \%)$ & $304(9.2 \%)$ \\
2059 & $4428(28.0 \%)$ & $398(9.0 \%)$ \\
\hline
\end{tabular}

\begin{tabular}{|c|c|c|c|}
\hline Outpatient & Percent & Indoor & Percent \\
\hline GOPD & 36 & $\begin{array}{l}\text { Antenatal \& } \\
\text { Postnatal }\end{array}$ & $44 \%$ \\
\hline Dental & 13.5 & Surgery & $29 \%$ \\
\hline Medical & $9 \%$ & Gynecology & $17 \%$ \\
\hline Pediatric & $8 \%$ & Medicine & $6 \%$ \\
\hline Eye & $6 \%$ & Ortho/ENT & $2 \%$ \\
\hline ENT & $6 \%$ & - & - \\
\hline $\begin{array}{l}\text { Obs/Gyn/Ortho/ } \\
\text { Derma }\end{array}$ & $5.5 \%$ & - & - \\
\hline Surgery & $5 \%$ & - & - \\
\hline
\end{tabular}


Kumar et al. An Experience of Optimizing A Community-Based Micro-Insurance Model to Bridge the Gap between Treatment Cost and ...

\begin{tabular}{|lll|}
\hline \multicolumn{3}{|l|}{$\begin{array}{l}\text { Table } \\
\text { (Undiscounted) in } \mathbf{3} \text { yrs variation. }\end{array}$} \\
\hline year & Hospital Charge NRs & Drug cost NRs \\
2057 & 423286.73 & 108101.71 \\
2058 & 2451990.00 & 370365.36 \\
2059 & 4844229.75 & 1270671.86 \\
\hline
\end{tabular}

\begin{tabular}{|ll|}
\hline \multicolumn{2}{|l|}{ Table 4. Common Morbidity pattern of Outpatient } \\
Diseases & \\
\hline Village people & Municipality People \\
(RURAL) & (URBAN) \\
Skin Disease & Hypertension \\
Acid peptic disease & Diabetes \\
Ovarian cyst & Urinary Infection \\
Pain abdomen & Pain Abdomen \\
Cholelithiasis & Cholelithiasis (Gallbladder. \\
(Gallbladder disease) & Problem) \\
Urinary Infection & COPD \\
Injury and URI & Respiratory Infection/ \\
\hline
\end{tabular}

*Source of tables - SHI BPKIHS

\begin{tabular}{|c|c|}
\hline \multicolumn{2}{|c|}{$\begin{array}{l}\text { Table 6. Frequency of Card in first year (Random } \\
\text { Sampling } \mathbf{n}=375 \text { ). }\end{array}$} \\
\hline Number of Times & Number of Card n (\%) \\
\hline 1 & $7(1.87)$ \\
\hline 2 & $15(4)$ \\
\hline 3 & $15(4)$ \\
\hline 4 & $4(1.07)$ \\
\hline 5 & $5(1.06)$ \\
\hline 6 & $10(2.66)$ \\
\hline 7 & $7(1.86)$ \\
\hline 8 & $3(0.8)$ \\
\hline 9 & $3(0.8)$ \\
\hline 10 & $4(1.07)$ \\
\hline 11 & $1(0.26)$ \\
\hline 12 & $1(0.26)$ \\
\hline 14 & $1(0.26)$ \\
\hline 15 & $1(0.26)$ \\
\hline
\end{tabular}

*Source of tables - SHI BPKIHS

\section{PRESENT SCENARIO OF SCHEMES IN NEPAL}

The SHI BPKIHS scheme is closed since 2006 by arguing the institute is incurring a big loss. In our study, three year data is showing acceptable situation considering the innovation and socially required action against 'disease burden'. The premium vs. expenditure ratio showed $47 \%$ difference in three years study i.e. 225:223 in the first year to 198:391 in the third year average of 3 years sharing 226:332. The institute is government owned and it claims to be community oriented but it has not taken care of several factors which was explained earlier. It has failed to put into practice its stated vision, mission and goals.

In private insurance, the premium is very high and variable with different companies. People either do not know about various policies or they ignore them because of high premium rates. Their policies also include several conditions of insured which exclude the risks. Contribution (Premium) is risk related, higher contribution in case of preexisting disease. In Nepalese context very few companies/organizations are insuring the people (formal sector) through private insurance.

United Mission to Nepal Model (UMN Type) voluntary insurance scheme was developed in 1978 and initiated the scheme in five health posts in one district. Present situation is not known. ${ }^{5}$

In Health cooperative model General federation of Nepalese trade unions (GEFONT) - Annual membership fees is RS100/- for membership and RS 30/- per month for insurance premium each member can include one member from family under the same premium GEFONT contributes RS.1500/-/month to health cooperative fund. Routine ANC at Health cooperative clinic or Kathmandu model hospital and delivery post-natal care services are given at Model hospital.

Present situation of individual payment in private/ government hospital the exclusion of poor is obvious. Only the very sick under acute conditions are paying. Healthy people do not have to incur any expense at all. The price vs. quality of service is also not taken care of, be it government sector or private sector. There was no control of price therefore poor population are major sufferer of disease which directly influences the longevity of people.

The measurement of burden is not only the price of service and paid premiums but much beyond that. ${ }^{6}$ If a person is sick he cannot work, so he is losing several days of work while he recovers, resulting in heavy loss of property and earning resources. Even when the person recovers physically, he is mentally burden by his loan he had taken for his treatment. SHI scheme is also based on social solidarity. The different premiums for city and villagers was to meet the equity principal and also to share burden of expenditures. ${ }^{7}$ The scheme has the conception of distributed burden spread over numbers of years and among a number of people. This scheme ran successfully in 2001 with the nonprofit concept. Increased popularity of scheme resulted in increase of group members getting insurance in subsequent years which was good but the defaulters and others stated problems increase the burden of the institute. For the scheme to succeed in the long term, people need to be 
convinced and made aware of its benefits.

It is impossible that a household of 5.5 people will all be sick over consecutive year. So some people may stay with the scheme for a year and then opt out of paying premiums especially if they believe that they are cured of disease. While implementing the scheme the disease pattern should be correlated with the country's morbidity pattern and no compromise be made in compulsory involvement of all households. For the scheme's smooth functioning, the PHC's health post and other health care provider should also be incorporated.

\section{WAY FORWARD}

This model of Scheme not popular (12\%) and Popular $(88 \%)$ among user of the scheme. Cost minimization and biased adverse risk enrolment are among the problems that need to be control. Institute authorities should have all the rights to analyze and modify the problems.
Various leak points will have to be plugged. In any such scheme the cost is distributed in volume and year. ${ }^{8}$ Discontinuation of the scheme on the basis of paid premium and expense is a diversion from community oriented philosophy. Poor and rich both should be made members of the scheme which is extremely useful for the community. It is human nature to demand more than what they pay so its duty of leaders to convince the public that we need healthy people to make healthy society. It may in its optimized form, become a model to be more widely adopted to bridge the gap between the cost of treatment and ability to pay in the developing country setting.

\section{ACKNOWLEDGEMENTS}

We acknowledge the participants involved in this research. We would also like to thank Miss Aayusha Gajurel for her kind help and support.

\section{Conflict of Interest: None.}

\section{REFERENCES}

1. Ron A, Smith BA, Tamburi G. Health Insurance in Developing countries. The social security approach- ILO Geneva. [Full Text]

2. ILO. C130 - Medical Care and Sickness Benefits Convention, 1969 (No. 130). ILO;Geneva:1969. [Full Text]

3. ILO. A case study on the health insurance scheme of B.P. Koirala Institute of health sciences in Nepal. ILO Office (STEP) Working paper February 2004. ILO;Kathmandu:2004. [Full Text]

4. ILO. Extending maternity protection to women in the informal economy - The case of Nepal (ILO Office). 2002. [Full Text]
5. Normand C, Weber A. Social Health Insurance - A guidebook for planning WHO/ILO publication.1994. [Full Text]

6. ILO. Social Health Protection. An ILO strategy towards universal access to health care. ILO;Geneva:1999. [Full Text]

7. World Bank. Financing health services in developing countries: an agenda for reform. A World Bank policy study. Washington DC;World Bank:1988. [Full Text]

8. ILO. Social Protection for People in the Informal Economy of Nepal. ILO:2004. [Full Text] 